Jurnal Biologi dan Pembelajarannya, Vol 7 No 2, Oktober 2020. Pp: 19-22

e-ISSN: $2406-8659$

\title{
PENGARUH MEDIA PEMBELAJARAN BYCARD ANIMALIA TERHADAP KEMAMPUAN BERPIKIR KRITIS SISWA KELAS X SMA/MA
}

\author{
Dewi Utari, Dwi Kameluh Agustina, dan Eva Nurul Malahayati \\ Universitas Islam Balitar \\ Email: utarrydhewii270@gmail.com
}

\begin{abstract}
Tujuan penelitian ini adalah untuk mengetahui pengaruh media pembelajaran Bycard Animalia terhadap kema mpuan berpikir kritis siswa. Desain yang digunakan dalam penelitian ini pretest-posttest control group design. $D$ ata dianalisis dengan pendekatan kuantitatif. Hasil yang didapat berdasarkan uji hipotesis pengaruh media pe mbelajaran Bycard Animalia terhadap berpikir kritis siswa menggunakan SPSS dengan uji Ancova, media Bycard berpengaruh sebesar 14,8\%. Disarankan kepada peneliti selanjutnya media pembelajaran Bycard Animalia dap at diterapkan dengan model pembelajaran yang berbasis masalah lainnya dan sebaiknya media pembelajaran Bycard Animalia diterapkan di sekolah yang sudah mempunyai kemampuan akademik yang tinggi agar menda pat hasil yang maksimal.
\end{abstract}

Kata Kunci: bycard animalia, kemampuan berpikir kritis, pengaruh.

\section{PENDAHULUAN}

Media pembelajaran adalah salah satu media yang dapat mendukung tercapainya pesan pembelajar an antara guru dengan siswa di kelas. Pemakain media pembelajaran dapat memberikan pengaruh tersendiri $d$ alam membangkitkan keinginan siswa untuk belajar, memberikan pengalaman konkret, bahakan membawa pe ngaruh psikologis terhadap siswa sehingga meningkatkan hasil belajar. Media pembelajaran yang dimanfaatkan guru berperan sebagai alat perantara guru dalam mengajar supaya mudah menangkap, memproses, dan meny ususn kembali informasi visual dan verbal. Berdasarkan dari hasil kuisioner dan wawancara kepada siswa dan $g$ uru di tiga sekolah di kota Blitar terkait media pembelajaran yang selama ini sudah digunakan guru dan siswa di peroleh data bahwa ada media alat peraga dengan persentase sebasar 33,61\%, media gambar dengan persen tase sebesar $47,05 \%$ dan media elektronik dengan persentase sebesar $16,80 \%$. Selain itu, berdasarkan hasil ob servasi awal menggunakan angket tertutup terkait kemampuan berpikir kritis siswa diperoleh hasil bahwa kem ampuan berpikir kritis siswa sebesar 57,90\% untuk aspek memberikan penjelasan sederhana, aspek memberika n penjelasan lebih lanjut 60,53\% dan 61,93\% untuk aspek mengatur strategi dan taktik. Output yang dihasilkan oleh proses pembelajaran dengan media seperti ini tidak lebih hanya menghasilkan siswa yang kurang mampu mengapresiasi ilmu pengetahuan, takut berpendapat, tidak berani mencoba yang akhirnya cenderung menjadi pelajaran yang pasif dan miskin kreatifitas [1]. Hal tersebut perlu mendapatkan solusi yang tepat sehingga hasil belajar siswa menjadi maksimal.

Ketersediaan media pembelajaran yang memadai, efektif, dan sesuai dengan materi yang sedang dip elajari dapat membantu siswa dalam memahami suatu materi serta membantu guru dalam melaksanakan pros es pembelajaran. Salah satu jenis media pembelajaran yang dapat digunakan adalah jenis media grafis. Media $g$ rafis merupakan media visual yang berfungsi menyalurkan pesan dari sumber pesan ke penerima pesan. Salura $\mathrm{n}$ yang digunakan mengutamakan indera penglihatan (visual) [2]. Gambar atau foto merupakan salah satu ciri $\mathrm{k}$ has media pembelajaran Bycard Animalia.

Pengembangan media Bycard Animalia diharapkan dapat memudahkan siswa untuk memahami pelaja ran biologi pada materi animalia karena dengan aktifitas yang menggunakan otak kanan dan juga otak kiri sehin gga dapat mengembangkan potensi siswa. Pembelajaran biologi yang dikenal berkaitan dengan cara mencari su atu fenomena, fakta, dan teori. Namun pembelajaran biologi bukan hanya sekedar mengkaji konsep-konsep, fa kta-fakta ataupun teori-teori tetapi juga merupakan proses penemuan yang akan menghasilkan suatu pengala man langsung yang dapat mengembangkan potensi siswa. Berpikir tingkat tinggi merupakan salah satu kemam puan yang dapat dikembangkan dalam pembelajaran biologi dan berpikir kritis merupakan salah satu ciri dari $b$ erpikir tingkat tinggi. Oleh karena itu, peneliti ingin mengetahui pengaruh media pembelajaran Bycard Animali $a$ berpengaruh terhadap kemempuan berpikir siswa. Penelitian serupa pernah dilakukan oleh $[3,4,5,6]$ yang me nghasilkan media pembelajaran Flashcard yang mampu meningkatkan hasil belajar dan berpikir kritis siswa.

\section{METODE PENELITIAN}


Jurnal Biologi dan Pembelajarannya, Vol 7 No 2, Oktober 2020. Pp: 19-22

e-ISSN: $2406-8659$

Penelitian ini menggunakan pendekatan kuantitatif jenis Quasi Eksperimental. Desain penelitian yang digunakan adalah Pretest-Posttest Control Group Design. Penelitian dilakukan di SMAN 4 Blitar pada bulan Febr uari-Maret 2019. Sampel penelitian sebanyak 35 siswa pada kelas eksperimen dan 35 siswa pada kelas kontrol. Data penelitian ini adalah kemampuan berpikir kritis siswa setelah menggunakan media Bycard Animalia yang $d$ iukur menggunakan instrumen sol tes essay yang diberikan pada kelas eksperimen dan kelas kontrol. Data kem ampuan berpikir kritis yang diukur antara lain 1)kemampuan memberikan penjelasan sederhana, 2) kemempua n menarik kesimpulan, 3) kemampuan memberikan penjelasan sederhana, 4)kemampuan berinteraksi dengan orang lain. Teknik analisis yang digunakan untuk mengukur kemampuan berpikir kritis adalah Analisis of Covari ant. Desain penelitian ditunjukkan pada Gambar 1.

$\begin{array}{llll}R & \mathrm{O}_{1} & \mathrm{X} & \mathrm{O}_{2} \\ \mathrm{R} & \mathrm{O}_{3} & \mathrm{O}_{4}\end{array}$

Gambar 1 Desain Penelitian Pretest-Posttest Control Group Design.

(Sumber diadaptasi Sugiyono, 2012)

Keterangan:

$\begin{array}{ll}\mathrm{R} & \text { : Kelompok atau kelas dipilih } \\ \mathrm{X} & \text { : Pembelajaran menggunakan Bycard Animalia } \\ \mathrm{O}_{1} & \text { : Hasil pretest kelas eksperimen } \\ \mathrm{O}_{3} & \text { : Hasil pretest kelas kontrol } \\ \mathrm{O}_{2} & \text { : Hasil posttes kelas eksperimen } \\ \mathrm{O}_{4} & \text { : Hasil posttest kelas kontrol }\end{array}$

\section{HASIL DAN PEMBAHASAN}

Data yang telah diperoleh dianalisis dengan uji Ancova. Hasil uji Ancova media pembelajaran bycard d itunjukkan pada Tabel 2.

Tabel 2. Hasil uji Ancova pengaruh media pembelajaran Bycard Animalia terhadap kemampuan berpikir kritis si swa

\begin{tabular}{|c|c|c|c|c|c|c|c|}
\hline \multicolumn{8}{|c|}{ Dependent Variable:Berpikir_Kritis } \\
\hline Source & $\begin{array}{c}\text { Type III Sum of S } \\
\text { quares }\end{array}$ & Df & & Mean Square & $\mathrm{F}$ & Sig. & $\begin{array}{c}\text { Partial Et } \\
\text { a Square } \\
\text { d }\end{array}$ \\
\hline $\begin{array}{l}\text { Corrected M } \\
\text { odel }\end{array}$ & $130.632^{\mathrm{a}}$ & & 2 & 65.316 & 43.188 & .000 & .556 \\
\hline Intercept & 326.047 & & 1 & 326.047 & 215.586 & .000 & .758 \\
\hline Pretest & 5.285 & & 1 & 5.285 & 3.494 & .000 & .148 \\
\hline Media_Ajar & 116.849 & & 1 & 116.849 & 77.262 & .000 & .528 \\
\hline Error & 104.354 & & 69 & 1.512 & & & \\
\hline Total & 26265.000 & & 72 & & & & \\
\hline $\begin{array}{l}\text { Corrected To } \\
\text { tal }\end{array}$ & 234.986 & & 71 & & & & \\
\hline
\end{tabular}

a. R Squared $=.556$ (Adjusted R Squared $=.543$ )

Berdasarkan Tabel, tes di berikan pada 2 kelas yaitu kelas control dan kelas eksperimen. Kelas ekspe rimen dengan menggunakan media pembelajaran Bycard Animalia dan kelas control yang tidak menggunakan media. Hasil uji lapang operasional dianalisis menggunakan uji ancova untuk melihat perbandingan dua kelas $d$ engan perlakuan yang berbeda. Analisis hasil menunjukkan bahwa besarnya pengaruh media ajar selaku perbe daan perlakuan sebesar $52,8 \%$ dan besarnya pengaruh pretest terhadap nilai posttest yaitu sebesar $14,8 \%$. Dari uji ancova didapat hasil yang meningkat, adapun faktor yang menyebabkan Bycard Animalia dapat mempengar uhi kemampuan berpikir siswa yaitu Bycard Animalia dikembangkan dengan menyajikan peristiwa- peristiwa $b$ 
Jurnal Biologi dan Pembelajarannya, Vol 7 No 2, Oktober 2020. Pp: 19-22

e-ISSN: $2406-8659$

erkaitan dengan filum-filum animalia yang terdapat dalam kehidupan sehari-hari sehingga dapat memacu pena saran siswa untuk menganalisis masalah yang muncul dalam peristiwa tersebut. [7] mengungkapkan bahwa pro ses pembelajaran yang mengacu pada analisis masalah merupakan salah satu pembelajaran yang bertumpu pa da penyelesaian masalah yang dihadapi secara ilmiah. Keunggualan pembelajaran berbasis masalah masalah in i diantaranya yaitu pemecahan masalah merupakan teknik yang cukup bagus untuk lebih memahami isi suatu $p$ elajaran, lebih menyenangkan, dapat meningkatkan aktivitas pembelajaran siswa, dan dapat mengembangkan kemampuan siswa untuk berpikir kritis dan mengembangkan kemampuan menyesuaikan dengan pengetahuan baru. Pengajaran dan pembelajaran kontekstual merupakan suatu konsepsi yang membantu guru mengaitkan $\mathrm{k}$ onten mata pelajaran dengan situasi dunia nyata dan memotivasi siswa membuat hubungan antara pengetahu an dan penerapannya.

Stimulus yang terdapat pada media pembelajaran Bycard Animalia menyajikan suatu masalah meng acu pada peristiwa nyata yang terdapat di kehidupan sehari-hari. [8] menyatakan bahwa konsep belajar yang $\mathrm{m}$ embantu guru mengaitkan antara materi yang diajarkan dengan situasi dunia nyata dan mendorong siswa mem buat hubungan antara pengetahuan yang dimilikinya dengan perencanaan dalam kehidupan sehari-hari. Pemb elajaran kontekstual bertujuan untuk melatih siswa agar dapat berpikir kritis dan terampil dalam memproses $p$ engetahuan agar dapat menemukan dan menciptakan suatu yang bermanfaat bagi dirinya sendiri dan orang lai n.

Pembahasan yang dimuat pada media pembelajaran Bycard Animalia singkat dan jelas agar memud ahkan siswa untuk menjawab hipotesis yang telah dimunculkan siswa. Dalam proses pembelajaran menggunak an media Bycard Animalia siswa mendiskusikan stimulus yang telah disajikan bersama kelompok kecil yang tela $\mathrm{h}$ dibuat, [9] berpendapat bahwa pembelajaran secara berkelompok yang terdiri dari empat sampai enam oran g yang mempunyai latar belakang kemampuan akademik, jenis kelamin, rasa tau suku yang berbeda (heterogen ) akan terjalin komunikasi serta interaksi yang terjadi antar peserta didik dapat memberikan suatu ide, mengan alisis, dan memecahkan masalah dari stimulus yang terdapat pada Bycard Animalia yang telah dikembangkan. $\mathrm{S}$ istem penilaian dilakukan terhadap kelompok setiap kelompok akan memperoleh reward, jika kelompok mamp u menunjukkan prestasi yang disyaratkan. Dengan demikian, setiap anggota kelompok akan mempunyai keterg antungan positif. Bycard Animalia dapat memunculkan semangat belajar dan rasa ingin tahu peserta didik, me mberi kesempatan kepada peserta didik untuk saling bekerjasama sehingga peserta didik dapat meningkatkan kemampuan berpikir kritis dalam mengikuti pembelajaran berlangsung, selain itu media juga berperan penting dalam kegiatan pembelajaran karena dapat membantu peserta didik memahami materi serta dapat membantu tercapainya materi yang dipelajari pada saat proses pembelajaran. Bukti empirik yang mendukung media pemb elajaran Bycard Animalia dapat meningkatkan berpikir kritis adalah hasil penelitian yang dilakukan oleh [10] ya ng menujukkan bahwa media Flashcard yang dikembangkan dapat digunakan untuk meningkatkan kemampua $\mathrm{n}$ berpikir kritis siswa.

Berpikir kritis menuntut upaya keras untuk memeriksa setiap keyakinan atau pengetahuan asumtif $b$ erdasarkan bukti pendukungnya dan kesimpulan-kesimpulan lanjutan yang diakibatkannya [11]. Sedangkan [12 ] menambahkan bahwa berpikir kritis adalah metode berpikir mengenai hal, subtansi atau masalah apa saja, di mana si pemikir meningkatkan kualitas pemikirannya dengan menangani secara terampil struktur-struktur yang melekat dalam pemikiran dan menerapkan standar-standar intelektual padanya. [13] memperkuat definisi diat as bahwa berpikir kritis adalah pemikiran yang masuk akal dan reflektif yang berfokus untuk memutuskan apa y ang mesti dipercaya atau dilakukan.

\section{KESIMPULAN}

Berdasarkan hasil penelitian yang diperoleh dapat disimpulkan bahwa media pembelajaran Bycard $\mathrm{A}$ nimalia berpengaruh terhadap kemempuan berpikir siswa sebesar $14,8 \%$.

\section{SARAN}

1. Disarankan pada peneliti selanjutnya, Bycard Animalia dapat diterapkan dengan model pembela jaran berbasis masalah lainnya, Problem solving, PJBL maupun Discovery Learning.

2. Bycard Animalia sebaiknya diterapkan di sekolah yang sudah mempunyai kemampuan akademik yang tinggi agar mendapat hasil yang maksimal

UCAPAN TERIMAKASIH

Universitas Islam Balitar dan SMA mitra 
Jurnal Biologi dan Pembelajarannya, Vol 7 No 2, Oktober 2020. Pp: 19-22

e-ISSN: $2406-8659$

\section{DAFTAR PUSTAKA}

[1] Sanaky, Dr. Hujair A., 2013, Media pembelajaran interaktif- inovatif, Yogyakarta, kaukaba dipantara.

[2] Hartato, K Dan Abduramansayah, 2009, Metode Pembelajaran Berbasis Active Learning, Palembang, Grafika Telindo.

[3] Fatimah, S., 2014, Pengembangan Media Flashcard Dalam Pembelajaran Matematika Untuk Siswa Kelas li Di Mi Ma'arif Sendang Kulon Progo, Skripsi, Ilmu Tarbiyah Dan Keguruan, Universitas Islam Negari Sunan Kalijaga Yogyakarta, Yogyakarta.

[4] Kurniawati, D. I., 2017, Pengembangan Media Flashcard Pada Pembelajaran Ipa Materi Cara Tumbuhan Menyesuaikan Diri Terhadap Lingkungannya Kelas V Sd Negeri Gundi Grobongan, Skripsi, Ilmu Pendidikan, Universitas Negeri Semarang, semarang.

[5] Fauzi, I. T., 2017, Pengembangan Media Flashcard Untuk Meningkatkan Minat Belajar Pada Mata Pelajaran Bahasa Indonesia Siswa Kelas li Di Mi Ma'arif Sendang Kulon Progo, Skripsi, Ilmu Tarbiyah Dan Keguruan, Universitas Islam Negari Sunan Kalijaga, Yogyakarta.

[6] Zuhriyah, A., 2017, Pengembangan Media Pembelajaran Flashcard Ipa Pada Anak Tunarungu Kelas Vii SMPLB, Skripsi, IImu Tarbiyah Dan Keguruan, Universitas Islam Negeri Raden Intan, Lampung.

[7] Sanjaya, W., 2006, Strategi Pembelajaran Berorientasi Standar Proses Pendidikan, Bandung, Kencana.

[8] Departemen Pendidikan Nasional, 2009, Pembelajaran Yangmengembangkan Criticall Thinking, Jakarta, Direktoral Jendral Menajemen Pendidikan Dasar Dan Menengah Atas

[9] Sanjaya, W., 2006, Strategi Pembelajaran Berorientasi Standar Proses Pendidikan, Bandung, Kencana.

[10] Purnasari, E., 2018, Pengaruh Model Project Baset Learning Berbasis Media Flashcard Terhadap Kemampuan Berpikir Kritis Peserta Didik Kelas X Pada Materi Protista Di SMA Muhammadiyah 2 Bandar Lampung, Skripsi, Tarbiyah Dan Keguruan, Universitas Islam Negeri Raden Intan, Lampung.

[11] Alec, F., 2008, Berpikir Kritis Sebuah Pengantar, Jakarta, Erlangga.

[12] Eggen, p., d., k., 2012, strageti dan model pembelajaran, Jakarta, PT Indek.

[13] Ennis, H. R., 1985, Critical Thinking, New Jersey, Prentice Hall. 